\title{
BMJ Open Hypothyroidism and related diseases: a methodological quality assessment of meta-analysis
}

\author{
Limin Tian, , ${ }^{1,3}$ Feifei Shao, ${ }^{2,3}$ Yahong Qin, ${ }^{2,3}$ Qian Guo, ${ }^{2,3}$ Cuixia Gao ${ }^{3,4}$
}

To cite: Tian L, Shao F, Qin Y, et al. Hypothyroidism and related diseases: a methodological quality assessment of metaanalysis. BMJ Open 2019;9:e024111. doi:10.1136/ bmjopen-2018-024111

- Prepublication history and additional material for this paper are available online. To view these files, please visit the journal online (http://dx.doi org/10.1136/bmjopen-2018024111).

Received 28 May 2018 Revised 10 January 2019 Accepted 5 February 2019

D) Check for updates

(C) Author(s) (or their employer(s)) 2019. Re-use permitted under CC BY-NC. No commercial re-use. See rights and permissions. Published by BMJ.

${ }^{1}$ School of Medicine, Lanzhou University, Lanzhou, China ${ }^{2}$ Department of Endocrinology (cadre ward 3), Gansu Provincial Hospital, Lanzhou, China ${ }^{3}$ Clinical Research Center for Metabolic Diseases, Gansu Provincial Hospital, Lanzhou, China

${ }^{4}$ Department of Ultrasonic Diagnosis, Gansu Provincial Hospital, Lanzhou, China

Correspondence to Limin Tian; tIm6666@sina.com

\begin{abstract}
Objectives There is an increasing prevalence of hypothyroidism and there is a growing body of metaanalyses (MAs) on the association between hypothyroidism and other diseases. However, the methodological quality of the MAs significantly varies. Thus, this study aimed to evaluate and summarise data on the methodological quality of MAs on the associations between hypothyroidism and other diseases using the Assessment of Multiple Systematic Reviews (AMSTAR) scale, providing suggestions for clinical decision-making processes.

Design To assess the methodological quality of MAs using the AMSTAR scale.

Data sources A systematic literature search was performed in PubMed, EMBASE, the Cochrane Library, web of science and Chinese Biomedicine Literature Database. Eligibility criteria We included MAs that had assessed the association between hypothyroidism and other diseases in humans and that had full texts regardless of the publication status. No restriction applied on language or date.
\end{abstract}

Data extraction and synthesis Two reviewers independently screened the titles and abstracts of all searched literature to acquire potentially eligible publications. The full texts of possible eligible publications were downloaded and assessed. Inconsistent comments were resolved through discussions with a third reviewer. Results 52 studies were included. The average AMSTAR score of the included articles was 8.6 (range: 5-10), and those of English and Chinese MAs were 8.8 and 7.0, respectively. A total of 52 MAs were evaluated, and 19 $(36.5 \%)$ and $33(63.5 \%)$ of these MAs were of moderate and high quality, respectively. None of the MAs were of Iow quality. Only two MAs had an a priori design. Items 3,5 and 9 had the highest compliance $(50 / 52,96.2 \%)$, and aside from item 1, items 7 and 8 had the lowest compliance (33/52,63.5\%). According to the results of these MAs, hypothyroidism was significantly associated with cardiovascular diseases, metabolic diseases, neuropsychiatric disorders, breast cancer and pregnancy outcome.

Conclusions The methodological quality of the included MAs on the association between hypothyroidism and other diseases was moderate to high. MAs with high qualities confirmed that hypothyroidism was significantly associated with cardiovascular diseases, metabolic syndrome, preterm birth and neonatal outcomes. Consideration of scientific quality when formulating conclusions should be made explicit and more attention should be paid
Strengths and limitations of this study

This study first assessed the methodological quality of meta-analyses (MAs) on the association between hypothyroidism and other diseases.

- We used the Assessment of Multiple Systematic Reviews (AMSTAR) scale to assess the methodological quality of MAs.

- The included MAs were randomly selected without restriction and followed rigorous inclusion and exclusion criteria.

- One limitation of this study is that the AMSTAR appraisal process was difficult to implement when the reporting quality was poor.

- We tried our best to make a conversion between $\mathrm{OR}$ and relative ratio by extracting raw data from MAs, but some data were not obtained.

to improving the methodological quality of MAs, and increasing their applicability for clinical decision-making.

\section{INTRODUCTION}

Hypothyroidism is defined as an increase in serum thyroid-stimulating hormone levels, with decreased (overt hypothyroidism $[\mathrm{OH}]$ ) or normal (subclinical hypothyroidism $[\mathrm{SCH}]$ ) serum thyroid hormone levels. ${ }^{1}$ Epidemiological data have indicated that the prevalence of hypothyroidism in the general population ranged from $4.6 \%$ to $23.5 \%,{ }^{2}$ and is predominant in elderly individuals and women. ${ }^{4} \mathrm{OH}$ is associated with weight gain, dyslipidaemia and hypertension, which are confounders of atherosclerosis and subsequently causes coronary heart disease $(\mathrm{CHD}){ }^{5}$ Prospective cohort studies have shown that $\mathrm{SCH}$ can increase the risk of heart failure (HF), ${ }^{6} \mathrm{CHD}$ events and mortality. ${ }^{7}$ Recently, Canpolat $e t a l^{8}$ have revealed that impaired gastric motility and resultant upper gastrointestinal symptoms were observed in individuals with $\mathrm{SCH}$, and thyroid hormone replacement was beneficial in improving symptoms and changes in clinical indicators. In addition, studies on 
the effects of SCH on cognitive impairment, ${ }^{9}{ }^{10}$ metabolic syndrome $(\mathrm{MetS})^{11}{ }^{12}$ and fractures ${ }^{1314}$ have shown conflicting results.

Meta-analyses (MAs) have been becoming a popular and powerful type of evidence, and they have several advantages, including overcoming the limitation of small sample sizes and pooling individual study results to generate a single best estimate. ${ }^{15}$ High-quality MAs can provide guideline developers better evidence to formulate guidelines, show the advantages and disadvantages of an intervention and guide health professionals, clinicians and stakeholders with the best interventions for targeted patients. ${ }^{16}$ The Cochrane Collaboration is an international network of healthcare professionals who prepare and regularly update systematic reviews (SRs), and Cochrane reviews were generally of high quality. ${ }^{15}$ In 2016, 73 reviews, which were completed by 11 Cochrane Review Groups, were used in 14 of 18 (78\%) WHO guidelines. ${ }^{17}$ By contrast, in MAs, a poor methodology can negatively affect decision-making processes. ${ }^{15}$ A great number of MAs that evaluate the role of hypothyroidism in the development and progression of other diseases have been published. However, the methodological quality of these MAs had not been evaluated, and the conclusions of these MAs were debatable.

Assessment of Multiple Systematic Reviews (AMSTAR), which was developed based on previous tools, empirical evidence and expert consensus and can be applied to SRs/MAs of both randomised controlled and non-randomised studies, is the most recent, reliable and valid tool for evaluating MAs. ${ }^{18}{ }^{19}$ Gagnier et al have assessed the methodological quality of SRs and MAs in the top five orthopaedic journals using AMSTAR. The included articles did not conform to the accepted standards of quality. Moreover, the validity of the published SRs is questionable, and their contribution to clinical decision-making is suboptimal. ${ }^{19}$ Remschmidt et al have used the AMSTAR to investigate the methodological quality of the SRs and MAs on influenza vaccination and identify influencing factors. ${ }^{20}$ Tian et al compared the methodological quality of SRs from China and the USA using the AMSTAR scale and concluded that the overall methodological quality of the SRs from China was similar to that from the USA. ${ }^{21}$

Thus, this study aimed to evaluate and summarise data on the methodological quality of MAs on the associations between hypothyroidism and other diseases using the AMSTAR scale, providing suggestions for clinical decision-making processes.

\section{MATERIALS AND METHODS}

\section{Data sources and study selection}

We performed a systematic literature search from inception to 1 April 2018 in PubMed, Embase, the Cochrane Library, Web of Science and Chinese Biomedical Literature Database to identify MAs on the associations between hypothyroidism and other diseases. The combinations of the following keywords were used in the search strategy: 'thyroid', 'hypothyroidism', 'subclinical hypothyroidism' and 'meta-analysis'. Free-text words and MeSH terms were entered depending on the characteristics of the database. Search strategy is shown in online supplementary appendix 1 . To minimise the risk of missing relevant literature, reference lists from retrieved articles were hand screened for additional applicable studies. We did not apply any restriction to language or date.

\section{Inclusion and exclusion criteria}

We included MAs that fulfilled the following criteria: (1) MAs that assessed the association between hypothyroidism and other diseases in humans (2) and that had full texts regardless of publication status, (3) studies in abstract form or meeting reports after the authors were contacted and full texts were obtained within a month, (4) recent studies with the same topic from the same author and (5) duplicate copies of MAs in both Chinese and English, including English articles.

\section{Study selection}

Two reviewers (FS and YQ) independently screened the titles and abstracts of all searched literature to acquire potentially eligible publications. The full texts of possible eligible publications were downloaded and assessed. Inconsistent comments were resolved through discussions with a third reviewer (LT).

\section{Assessment of methodological quality of the included MAs}

Two authors (FS and YQ) independently assessed the methodological quality of the included MAs. The AMSTAR scale, which uses an 11-item questionnaire, was used in this study to assess the methodological quality of MAs because it is the most recent, reliable and valid tool. ${ }^{22}$ The items in the AMSTAR scale are the following: an a priori design, duplicate study selection and data extraction, comprehensive literature search, use of the status of publication as an inclusion criteria, a list of included and excluded studies, characteristics of included studies, documented assessment of the scientific quality of the included studies, appropriate use of the scientific quality in forming conclusions, appropriate use of methods to combine the findings of studies, assessment of the likelihood of publication bias and documentation of potential conflicts of interest. The items may be answered with a 'yes', 'no', 'can't answer' or 'not applicable' . One point was provided when the answer was 'Yes'; otherwise, no score was provided. The AMSTAR quality score was the summation of the number of 'yes'. According to the number of criteria met, the included articles were ranked into three levels: 'high' (range: 9-11), 'moderate' (range: 5-8) and 'low' (range: 0-4).

\section{Agreement of assessment}

To obtain more reliable data on the methodological quality of MAs, the agreement of the methodological quality assessment results between the two independent reviewers (FS and $\mathrm{YQ}$ ) was investigated through a plot test. In this process, 10 MAs were selected from the included 
studies. The two reviewers independently assessed the methodological quality of these MAs using the AMSTAR scale. We calculated the agreement proportion and Cohen's kappa (k) value for each of the 11 AMSTAR items. A $\mathrm{k}$ value between 0.81 and 1.00 indicated a good agreement. ${ }^{23}$ During the first assessment, the agreement for items 7 and 8 between the two reviewers were poor (0.67 and 0.70, respectively), and good agreement was obtained after a discussion between the reviewers.

\section{Patient involvement}

Given its methodological focus, we did not evaluate patient-related outcomes. Therefore, we also chose not to involve patients' input in its design. However, the aim of this study is to indirectly benefit the welfare of patients by promoting the development of high-quality MAs.

\section{RESULTS}

\section{Study identification}

Initially, we yielded 3107 potentially relevant articles by searching the five electronic databases and other sources. After identifying duplications and screening the titles and abstracts, 3039 articles were excluded. We attempted to find the full texts of the remaining 68 articles for intensive reading. Of these, 12 articles that met the criteria were published as abstracts. Moreover, we aimed to obtain the full texts by contacting the authors. However, the authors did not respond within a month. Thus, these articles were excluded. Two Chinese $\operatorname{articles}^{24}{ }^{25}$ were excluded from publishing in both Chinese and English languages. In addition, two MAs ${ }^{26} 27$ were excluded from the old version. Thus, we only included the recently updated ones. ${ }^{28}$ Finally, 52 eligible MAs were included in our analysis. The flowchart of the review selection process is presented in figure 1.

\section{Characteristics of the included MAs}

Among the 52 included eligible MAs, 46 ${ }^{28-73}(46 / 52$, $88.5 \%)$ were published in English, and the rest ${ }^{74-79}(6 / 52$, $11.5 \%$ ) were published in Chinese. The 52 included MAs contained 685 studies, with an average of 13.2 (range: 3-39) studies per article. The publication years of the included articles ranged from 2008 to 2018 , and $82.7 \%$ of the articles were published in the last 5 years. The characteristics of the 52 MAs are shown in online supplementary appendix 2.

Ten $^{39} 40434957586568-70$ MAs were about the associations between $\mathrm{OH}$ and other diseases, and $35^{28-36} 3842$ 44-47 50-56 59-64 $66 \quad 67$ 75-79 MAs have shown the associations between SCH and other diseases. Seven ${ }^{37} 4148$ 71-74 MAs have investigated the effects of both $\mathrm{OH}$ and $\mathrm{SCH}$ on other diseases. Except for the general population, pregnant women with hypothyroidism were also included in the target groups of the included MAs. ${ }^{35} 37404148516164677174$ The characteristics of these MAs are shown in table 1.

\section{Methodological quality of the included MAs}

The average AMSTAR score of the included articles was 8.6 (range: 5-10), and those of English and Chinese MAs were 8.8 and 7.0 , respectively. A total of 52 MAs were evaluated, and $19(36.5 \%)$ and $33(63.5 \%)$ of these MAs were of moderate and high quality. None of the MAs was of low quality. The numbers and percentages of each response ('yes', 'no', 'can't answer' and 'not applicable') among

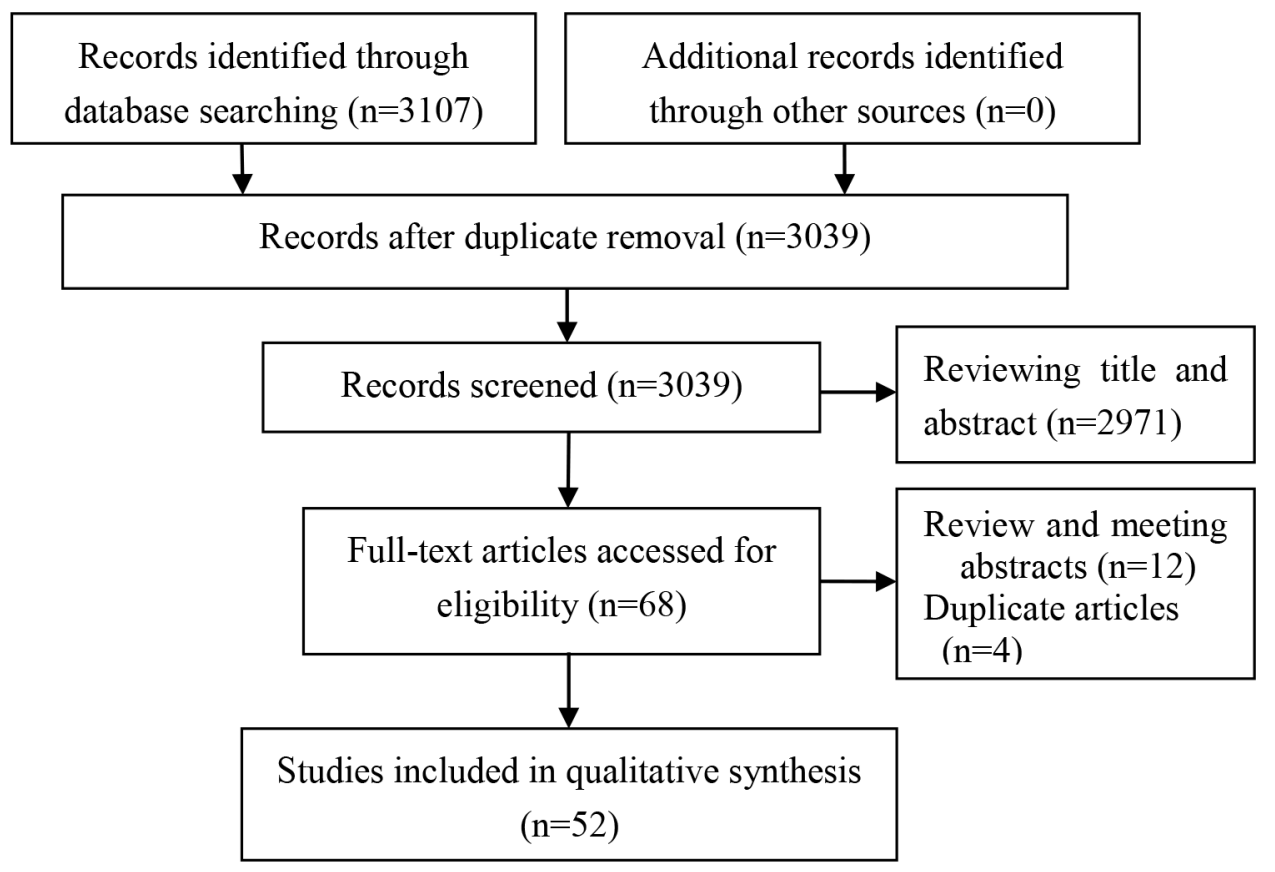

Figure 1 Flow chart of the review search and identification. 


\begin{tabular}{ll}
\hline Table 1 Characteristics of MAs & \\
\hline Characteristics of MAs & No of MAs \\
\hline Target groups & 40 \\
General population with $\mathrm{OH}$ or SCH & 12 \\
Pregnant women with $\mathrm{OH}$ or SCH &
\end{tabular}

Associated diseases

\begin{tabular}{|c|c|}
\hline Cardiovascular events & 7 \\
\hline Preterm birth & 6 \\
\hline Fracture & 5 \\
\hline Carotid intima-media thickness & 4 \\
\hline Neonatal outcomes & 4 \\
\hline Cognitive function & 3 \\
\hline $\begin{array}{l}\text { Intelligence development of the } \\
\text { offspring }\end{array}$ & 3 \\
\hline Blood pressure & 3 \\
\hline Metabolic syndrome & 2 \\
\hline Serum lipid level & 2 \\
\hline Breast cancer & 2 \\
\hline Chronic kidney disease & 2 \\
\hline Glaucoma & 2 \\
\hline Diabetes complications & 2 \\
\hline Non-alcoholic fatty liver disease & 2 \\
\hline Intrauterine growth restriction & 2 \\
\hline Left ventricular diastolic function & 1 \\
\hline Stroke & 1 \\
\hline Plasma homocysteine status & 1 \\
\hline Carpal tunnel syndrome & 1 \\
\hline Obstructive sleep apnoea & 1 \\
\hline Gestational diabetes & 1 \\
\hline Metabolic and hormonal profile & 1 \\
\hline Miscarriage & 1 \\
\hline \multicolumn{2}{|l|}{ Language } \\
\hline English & 46 \\
\hline Chinese & 6 \\
\hline \multicolumn{2}{|l|}{ Publication year } \\
\hline 2008-2010 & 3 \\
\hline 2011-2013 & 6 \\
\hline 2014-2016 & 27 \\
\hline 2017-2018 & 16 \\
\hline \multicolumn{2}{|l|}{ Impact factor } \\
\hline$<3.5$ & 24 \\
\hline$\geq 3.5$ & 20 \\
\hline
\end{tabular}

$\mathrm{OH}$,overt hypothyroidism; MAs, meta-analyses; $\mathrm{SCH}$, subclinical hypothyroidism

the MAs for each AMSTAR item are shown in table 2. Two MAs had an a priori design. Items 3,5 and 9 had the highest compliance $(50 / 52,96.2 \%)$, and aside from item
1 , items on whether the scientific quality of the included studies was assessed and documented and whether the scientific quality of the included studies has been used appropriately in formulating conclusions had the lowest compliance $35 / 52(67.3 \%)$. For item 7 , the NewcastleOttawa Scale, the most commonly used tool for observational studies, was used.

\section{Association between hypothyroidism and other diseases}

Conclusions and the number of MAs, case-control (CC) / cohort (CO)/cross-sectional (CS) studies and patients, and average AMSTAR score about the association between hypothyroidism and other diseases are shown in tables 3 and 4.

According to the AMSTAR score and the number of patients included in these MAs, the association between hypothyroidism and other diseases was summarised by showing the relative ratio (RR)/OR/HR/weighted mean difference/standardised mean difference (tables 5 and 6). Regarding the association between $\mathrm{SCH}$ and other diseases, diabetic peripheral neuropathy had the highest RR value (2.27) and OR value (1.87). The association between $\mathrm{OH}$ and breast cancer had the highest OR (1.79). However, this value is not considered statistically significant.

\section{DISCUSSION}

In view of the growing expansion of MAs that are related to the association between hypothyroidism and other diseases, the methodological quality of these articles was investigated. To the best of our knowledge, this study first used the AMSTAR tool to evaluate the quality of MAs in this field. The AMSTAR tool is the recommended scale for assessing design progress and minimising bias in research.

The methodological quality of the included MAs was moderate to high. Various flaws regarding the information in the included articles were found, and the main problems were the following.

First, to increase scientific credibility and improve research standards, a standard protocol for MAs must be designed. A protocol can make the research process prospective, strict and transparent. In this study, only two $\mathrm{MAs}^{61} 72$ provided an a priori study design. Whether the authors had been influenced by the published articles during a certain process in preparing the MAs is challenging to assess. Therefore, more attention should be provided in drafting the protocol.

Second, to avoid inappropriate inclusion or exclusion of articles and minimise selection bias, the AMSTAR scale recommends that at least two independent reviewers should obtain results and data. In this study, eight (15.4\%) studies did not follow this recommendation, which may increase selection bias and decrease the quality of the included MAs.

Moreover, the AMSTAR scale suggested that a comprehensive search strategy with a systematic search plan and wide retrieval range should be developed. The former 
Table 2 Methodological quality of the included MAs

\begin{tabular}{|c|c|c|c|c|}
\hline Items & Y, n (\%) & $\mathbf{N}, \mathbf{n}(\%)$ & CA, n (\%) & NA, $n(\%)$ \\
\hline 1. Was an 'a priori' design provided? & $2(3.8)$ & $50(96.2)$ & $0(0)$ & $0(0)$ \\
\hline 2. Was there duplicate study selection and data extraction? & $44(84.6)$ & $1(1.9)$ & $7(13.5)$ & $0(0)$ \\
\hline 3. Was a comprehensive literature search performed? & $51(98.1)$ & $1(1.9)$ & $0(0)$ & $0(0)$ \\
\hline 4. Was the status of publication used as an inclusion criterion? & $44(84.6)$ & $8(15.4)$ & $0(0)$ & $0(0)$ \\
\hline 5. Was a list of studies provided? & $51(98.1)$ & $1(1.9)$ & $0(0)$ & $0(0)$ \\
\hline 6. Were the characteristics of the included studies provided? & $50(96.2)$ & $2(3.8)$ & $0(0)$ & $0(0)$ \\
\hline $\begin{array}{l}\text { 7. Was the scientific quality of the included studies assessed and } \\
\text { documented? }\end{array}$ & $38(73.1)$ & $14(26.9)$ & $0(0)$ & $0(0)$ \\
\hline $\begin{array}{l}\text { 8. Was the scientific quality of the included studies used appropriately in } \\
\text { formulating conclusions? }\end{array}$ & $35(67.3)$ & $17(32.7)$ & $0(0)$ & $0(0)$ \\
\hline 9. Were the methods used to combine the findings of studies appropriate? & $50(96.2)$ & $2(3.8)$ & $0(0)$ & $0(0)$ \\
\hline 10. Was the likelihood of publication bias assessed? & $44(84.6)$ & $8(15.4)$ & $0(0)$ & $0(0)$ \\
\hline 11. Was the conflict of interest stated? & 40 (76.9) & $12(23.1)$ & $0(0)$ & $0(0)$ \\
\hline
\end{tabular}

Y, yes; N, no; CA, cannot answer; NA, not applicable.

Table 3 Conclusions, the number of MAs, average CC/CO/CS studies and patients and average AMSTAR score about the association between $\mathrm{OH}$ and other diseases

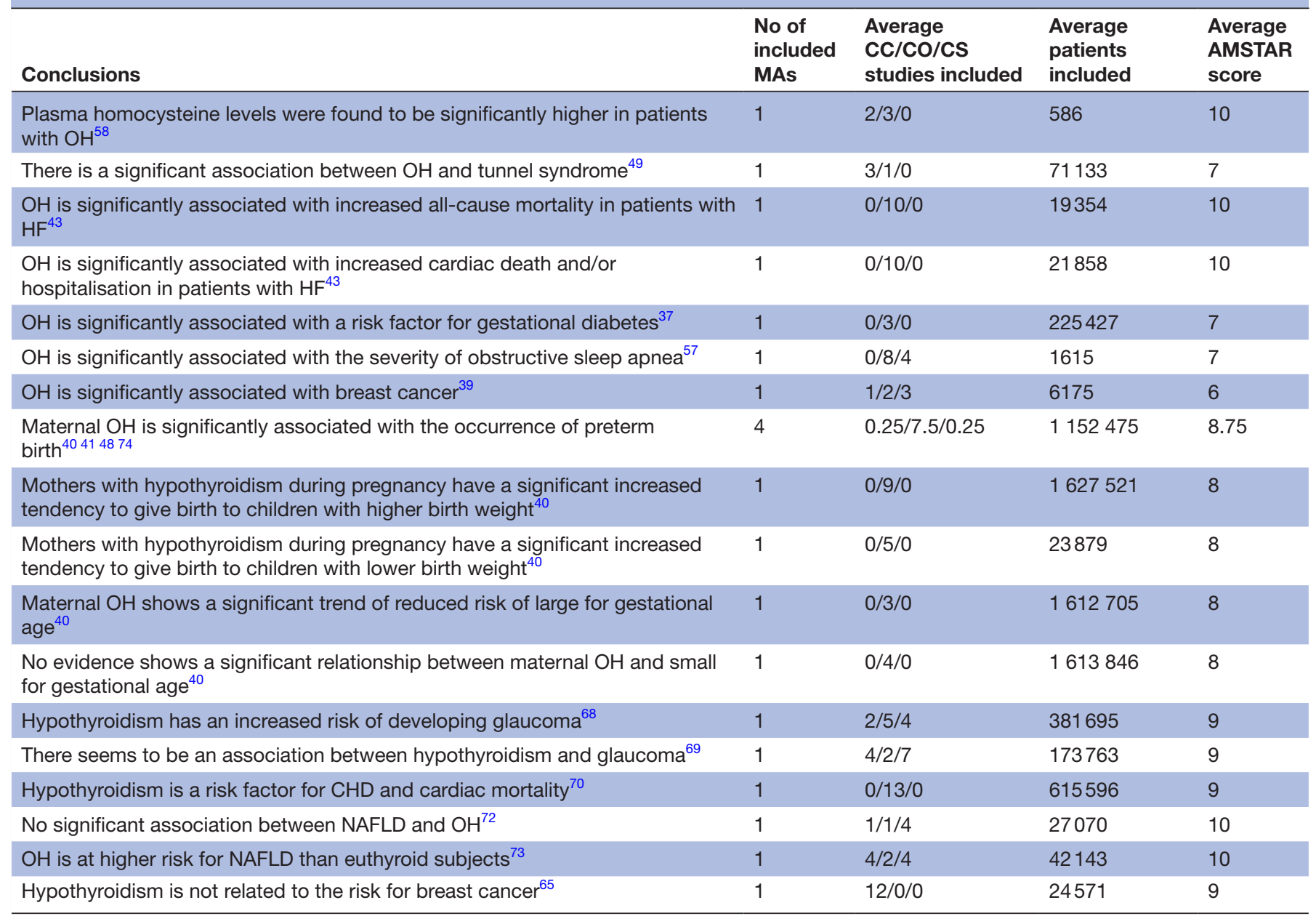

AMSTAR, Assessment of Multiple Systematic Reviews; CC/CO/CS; case-control/cohort/cross-sectional; CHD, coronary heart disease; HF, heart failure; MAs, meta-analyses; NAFLD, non-alcoholic fatty liver disease; $\mathrm{OH}$, overt hypothyroidism. 
Table 4 Conclusions, the number of MAs, average CC/CO/CS studies and patients and average AMSTAR score about the association between $\mathrm{SCH}$ and other diseases

\begin{tabular}{|c|c|c|c|c|}
\hline Conclusions & $\begin{array}{l}\text { No of } \\
\text { included } \\
\text { MAs }\end{array}$ & $\begin{array}{l}\text { Average } \\
\mathrm{CC} / \mathrm{CO} / \mathrm{CS} \\
\text { studies included }\end{array}$ & $\begin{array}{l}\text { Average } \\
\text { patients } \\
\text { included }\end{array}$ & $\begin{array}{l}\text { Average } \\
\text { AMSTAR } \\
\text { score }\end{array}$ \\
\hline $\begin{array}{l}\text { Plasma homocysteine levels were not found to be significantly higher in } \\
\text { patients with } \mathrm{SCH}^{58}\end{array}$ & 1 & $3 / 5 / 0$ & 926 & 10.00 \\
\hline $\mathrm{SCH}$ is not significantly associated with fractures ${ }^{305254}$ & 3 & 0/8/0 & 128667 & 9.7 \\
\hline $\begin{array}{l}\mathrm{SCH} \text { was associated with increased risk of any location of fractures, hip } \\
\text { fractures and forearm fractures }{ }^{60}\end{array}$ & 1 & $0 / 13 / 0$ & 62490 & 10 \\
\hline $\begin{array}{l}\text { No evidence which could prove a definite association between } \mathrm{SCH} \text { and } \\
\text { the risk of fracture }\end{array}$ & 1 & $0 / 6 / 0$ & 289575 & 7 \\
\hline $\begin{array}{l}\text { Serum TC, LDL-C and TG levels were significantly increased in patients } \\
\text { with SCH compared with euthyroidism individuals. No significant } \\
\text { difference was observed for serum HDL-C } \mathrm{C}^{3642}\end{array}$ & 2 & $5 / 0 / 7$ & 22767 & 9.00 \\
\hline $\mathrm{SCH}$ is associated with a significant decrease in fasting plasma glucose $\mathrm{e}^{36}$ & 1 & $3 / 0 / 1$ & 3507 & 9.00 \\
\hline $\mathrm{SCH}$ is not significantly associated with $\mathrm{BM}^{36}$ & 1 & $7 / 0 / 1$ & 3971 & 9.00 \\
\hline $\mathrm{SCH}$ was associated with a significant increase in SBP 313656 & 3 & $1.7 / 2 / 7$ & 23485 & 8.00 \\
\hline $\mathrm{SCH}$ was associated with a significant increase in $\mathrm{DBP}^{31}$ & 1 & $0 / 0 / 6$ & 17323 & 8.00 \\
\hline $\mathrm{SCH}$ is not significantly associated with increased $\mathrm{DBP}^{36} 56$ & 2 & $1.7 / 1.7 / 5$ & 25810 & 8.00 \\
\hline $\mathrm{SCH}$ is associated with a significant increase in C-IMT ${ }^{36} 596675$ & 4 & $6.75 / 3.5 / 0.5$ & 2420 & 8.75 \\
\hline $\begin{array}{l}\text { SCH has a significant association with arterial wall thickening and } \\
\text { stiffening and endothelial dysfunction and increased risk of cardiovascular } \\
\text { events }{ }^{59}\end{array}$ & 1 & $27 / 0 / 0$ & 1931 & 9 \\
\hline $\mathrm{SCH}$ is significantly associated with an increased risk for $\mathrm{CHD}^{5063}$ & 2 & $0 / 6.5 / 1$ & 8528 & 7.5 \\
\hline $\mathrm{SCH}$ is not significantly associated with an increased risk for $\mathrm{CHD}^{2844} 77$ & & 0/9.3/0 & 18525 & 7.30 \\
\hline $\begin{array}{l}\mathrm{SCH} \text { is significantly associated with an increased risk for cardiovascular } \\
\text { mortality }{ }^{50} 63\end{array}$ & 2 & $0 / 3.5 / 0.5$ & 6525 & 7.5 \\
\hline $\begin{array}{l}\mathrm{SCH} \text { is not significantly associated with an increased risk for } \\
\text { cardiovascular mortality } 2844\end{array}$ & 2 & $0 / 10 / 0$ & 33444 & 8.00 \\
\hline $\begin{array}{l}\mathrm{SCH} \text { is not significantly associated with an increased risk for all-cause } \\
\text { mortality }{ }^{28} 4450\end{array}$ & 3 & $0 / 6.3 / 0.3$ & 24853 & 7.00 \\
\hline $\mathrm{SCH}$ is significantly associated with MetS as defined by the IDF Criteria ${ }^{55}$ & 1 & $0 / 0 / 2$ & 7258 & 10.00 \\
\hline $\begin{array}{l}\text { SCH is not significantly associated with MetS as defined by the NCEP- } \\
\text { ATP III Criteria } \\
\text { 34 55 }\end{array}$ & 2 & $2 / 0 / 5$ & 24717 & 10.00 \\
\hline $\begin{array}{l}\mathrm{SCH} \text { is not significantly associated with MetS as defined by the Chinese } \\
\text { Criteria }^{55}\end{array}$ & 1 & $0 / 0 / 1$ & 1399 & 10.00 \\
\hline $\begin{array}{l}\mathrm{SCH} \text { is not significantly associated with MetS as defined by the Japanese } \\
\text { Criteria }^{55}\end{array}$ & 1 & $0 / 0 / 2$ & 10350 & 10.00 \\
\hline $\mathrm{SCH}$ is not significantly associated with cognitive impairment ${ }^{29} 4547$ & 3 & 0/8.3/4.3 & 16833 & 9.33 \\
\hline $\begin{array}{l}\text { SCH patients had significantly worse parameters of left ventricular } \\
\text { diastolic function than euthyroid subjects aged }<60 \text { years }{ }^{33}\end{array}$ & 1 & $0 / 0 / 14$ & 675 & 7.00 \\
\hline $\mathrm{SCH}$ is significantly associated with a risk factor for gestational diabetes ${ }^{37}$ & 1 & $0 / 6 / 0$ & 63567 & 7 \\
\hline $\begin{array}{l}\text { SCH can significantly increase the risk of diabetic retinopathy in T2DM } \\
\text { patients }\end{array}$ & 2 & $0 / 8.5 / 0.5$ & 4101 & 9.5 \\
\hline $\begin{array}{l}\mathrm{SCH} \text { can significantly increase the risk of diabetic nephropathy in T2DM } \\
\text { patients }^{3862}\end{array}$ & 2 & $6 / 0 / 1.5$ & 2653 & 8.5 \\
\hline $\begin{array}{l}\mathrm{SCH} \text { can significantly increase the risk of diabetic peripheral neuropathy } \\
\text { in T2DM patients }\end{array}$ & 1 & $3 / 0 / 0$ & 1710 & 10 \\
\hline $\begin{array}{l}\text { SCH can significantly increase the risk of peripheral arterial disease in } \\
\text { T2DM patients }{ }^{38}\end{array}$ & 1 & $4 / 0 / 0$ & 801 & 10 \\
\hline
\end{tabular}




\begin{tabular}{|c|c|c|c|c|}
\hline Conclusions & $\begin{array}{l}\text { No of } \\
\text { included } \\
\text { MAs }\end{array}$ & $\begin{array}{l}\text { Average } \\
\text { CC/CO/CS } \\
\text { studies included }\end{array}$ & $\begin{array}{l}\text { Average } \\
\text { patients } \\
\text { included }\end{array}$ & $\begin{array}{l}\text { Average } \\
\text { AMSTAR } \\
\text { score }\end{array}$ \\
\hline $\begin{array}{l}\text { SCH is a significant risk factor of chronic kidney disease in T2DM } \\
\text { patients }^{78}\end{array}$ & 1 & $4 / 0 / 2$ & 38284 & 6 \\
\hline $\begin{array}{l}\text { SCH does not influence the hormonal profile of women with polycystic } \\
\text { ovary syndrome. But it results in mild metabolic abnormalities in a short- } \\
\text { term setting }\end{array}$ & 1 & $0 / 12 / 0$ & 2341 & 10 \\
\hline $\begin{array}{l}\text { Maternal SCH is not significantly associated with the occurrence of } \\
\text { preterm birth }{ }^{48}\end{array}$ & 1 & $0 / 10 / 0$ & 48684 & 8 \\
\hline $\begin{array}{l}\text { Maternal SCH has a significant adverse affect on the intelligence of } \\
\text { offspring }{ }^{354676}\end{array}$ & 3 & $1 / 0 / 37$ & 303360 & 8.3 \\
\hline $\mathrm{SCH}$ patients have a higher prevalence of miscarriage ${ }^{67}$ & 1 & $0 / 3 / 0$ & 6036 & 9 \\
\hline $\begin{array}{l}\text { Children of women with } \mathrm{SCH} \text { were found have a significant lower mean } \\
\text { motor scores than those of euthyroidism }{ }^{35}\end{array}$ & 1 & $0 / 1 / 0$ & 160 & 10 \\
\hline No significant association was found between NAFLD and $\mathrm{SCH}^{72}$ & 1 & $0 / 1 / 4$ & 26454 & 10 \\
\hline
\end{tabular}

AMSTAR, Assessment of Multiple Systematic Reviews; BMI, body mass index; CC/CO/CS, case-control/cohort/cross-sectional; CHD, coronary heart disease; C-IMT, carotid intima-media thickness; DBP, diastolic blood pressure; HDL-C, high-density lipoprotein cholesterol; IDF, International Diabetes Federation; LDL-C, low-density lipoprotein cholesterol; MAs, meta-analyses; MetS, metabolic syndrome; NAFLD, non-alcoholic fatty liver disease; NCEP-ATP III, National Cholesterol Education Programme's Adult Treatment Panel III; SBP, systolic blood pressure; $\mathrm{SCH}$, subclinical hypothyroidism; TC, total cholesterol; TG, total triglyceride; T2DM, type 2 diabetes mellitus.

refers to keywords and retrieval types, and the latter indicates that at least two databases should be searched. In addition, item 3 emphasised that supplemental searching is also significantly important. Similarly, to ensure a comprehensive search and decrease selection bias, the fourth AMSTAR scale recommends that the status of publication should not be restricted, which include grey articles and published language. The authors are all willing to obtain positive outcomes, and journals published articles with positive outcomes. However, articles with negative outcomes are not usually published or only published in informal journals. The inclusion of grey articles is significant in decreasing selection bias. For item 3 , one $^{44}$ article was not in accordance to this item. However, for item $4,15.4 \%(8 / 52)^{2837454851577677}$ of the studies did not consider using published literature, which might result in selection bias.

The AMSTAR scale also suggests that a list of both the included and excluded articles should be provided. The included and excluded articles list can explicitly show the qualities of the selected articles. However, due to restricted page layouts, apart from the Cochrane MAs, most articles only listed the included articles. In this study, 51 MAs included an articles list, and one ${ }^{49}$ article had neither included nor excluded a list of articles.
The sixth item focuses on whether the characteristics of the included studies were provided. In this study, most $(96.1 \%)$ of the included articles described subject, gender, age and other characteristics of included articles.

Items 7 and 8 recommend the assessment of the scientific quality of the original articles and consideration of the scientific quality when formulating conclusions, which should be based on scientific and cautious research results to provide an objective and reasonable suggestion for clinical professionals and stakeholders. Nineteen $(36.5 \%)^{31} 33363739445053565759616270-72$ 77-79 MAs did not assess the scientific quality of the included studies, which might decrease the credibility of the conclusions.

Thus, publication bias should be assessed in every MA according to the Cochrane handbook for the SRs of interventions, ${ }^{80}$ which can be performed by using a certain statistical test method or chart. ${ }^{81}$ Among the 52 included articles, seven ${ }^{29} 405054576265$ failed to assess publication bias, and all of which were Chinese articles. Another area of concern is the lack of reports on the conflict of interest among the authors of the MAs. Readers should know whether the results of the MAs are influenced by any funders. In our results, $23.1 \%$ $(12 / 52)^{33506267-6974-79}$ of the authors did not declare any conflict of interest. 
Table 5 Association between $\mathrm{SCH} / \mathrm{OH}$ and other diseases (showed by RR/HR/OR)

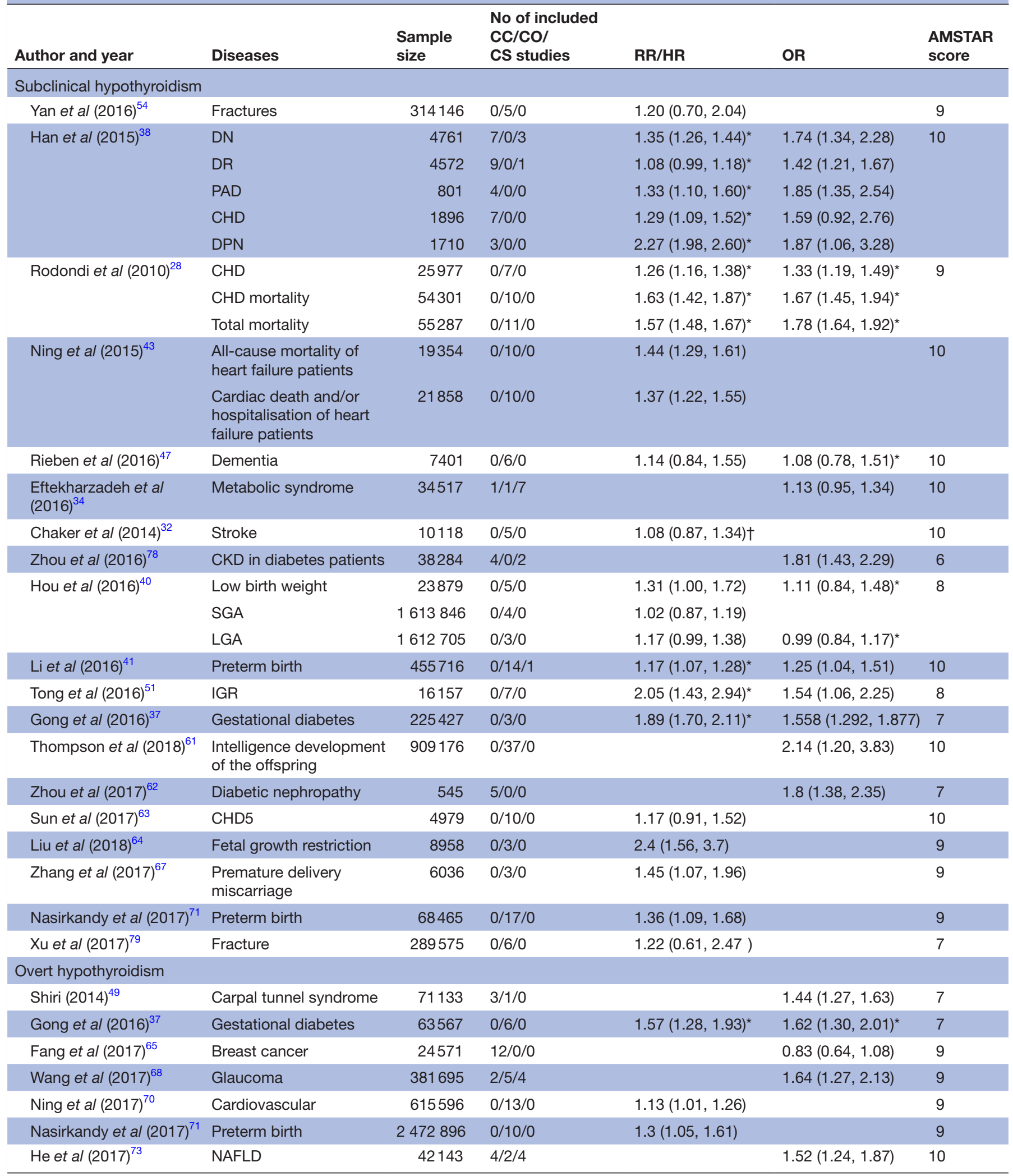

${ }^{*}$ The RR or OR calculated according to the sample size.

${ }^{* *}+\mathrm{HR}$.

AMSTAR, Assessment of Multiple Systematic Reviews; CC /CO /CS , case-control/cohort/cross-sectional ; CHD, coronary heart disease; CKD, chronic kidney diseases; DPN, diabetic peripheral neuropathy; DN, diabetic nephropathy; DR, diabetic retinopathy; HR, hazard ratio; IGR, intrauterine growth restriction; LGA, large for gestational age; NAFLD, non- alcoholic fatty liver disease; PAD, peripheral arterial disease; RR, relative ratio; SGA, small for gestational age. 
Table 6 Association between $\mathrm{SCH} / \mathrm{OH}$ and other diseases (showed by WMD/SMD)

\begin{tabular}{|c|c|c|c|c|c|}
\hline Author and year & Diseases & $\begin{array}{l}\text { Sample } \\
\text { size }\end{array}$ & $\begin{array}{l}\text { No of included } \\
\mathrm{CC} / \mathrm{CO} / \\
\text { CS studies }\end{array}$ & WMD/SMD (95\% Cl) & $\begin{array}{l}\text { AMSTAR } \\
\text { score }\end{array}$ \\
\hline \multicolumn{6}{|c|}{ Subclinical hypothyroidism } \\
\hline \multirow[t]{2}{*}{ Ye et al (2014) } & SBP & 50147 & $0 / 6 / 14$ & $1.47 \mathrm{~mm} \mathrm{Hg}(0.54$ to $2.39 \mathrm{~mm} \mathrm{Hg}), \mathrm{p}=0.002$ & 8 \\
\hline & DBP & 48636 & $0 / 5 / 14$ & $0.44 \mathrm{~mm} \mathrm{Hg}(-0.15$ to $1.02 \mathrm{~mm} \mathrm{Hg}), \mathrm{p}=0.142$ & \\
\hline \multirow[t]{3}{*}{ Liu et al $(2014)^{42}$} & TC level & 40546 & $3 / 0 / 13$ & $12.17 \mathrm{mg} / \mathrm{dL}$ (7.79 to $16.54 \mathrm{mg} / \mathrm{dL}), \mathrm{p}<0.001$ & 10 \\
\hline & HDL-C level & 40559 & $3 / 0 / 13$ & $-0.50 \mathrm{mg} / \mathrm{dL}(-1.90$ to $0.89 \mathrm{mg} / \mathrm{dL}), \mathrm{p}=0.481$ & \\
\hline & TG level & 40420 & $3 / 0 / 11$ & $13.19 \mathrm{mg} / \mathrm{dL}$ (4.92 to $21.46 \mathrm{mg} / \mathrm{dL}), p<0.001$ & \\
\hline Zhou et al (2014) & $\begin{array}{l}\text { Plasma } \\
\text { homocysteine status }\end{array}$ & 926 & $0 / 8 / 0$ & $0.07(-0.10$ to 0.24$), p=0.425^{\star}$ & 10 \\
\hline $\begin{array}{l}\text { Wang et al } \\
(2013)^{75}\end{array}$ & C-IMT & 4551 & $0 / 0 / 9$ & $0.05 \mathrm{~mm}(0.02$ to $0.07 \mathrm{~mm}), \mathrm{p}=0.000$ & 9 \\
\hline Aziz et al $(2017)^{66}$ & C-IMT & 543 & 9 clinical trials & $0.44 \mathrm{~mm} \mathrm{Hg}(0.14$ to 0.74$), p=0.004$ & 10 \\
\hline \multicolumn{6}{|l|}{ Overt hypothyroidism } \\
\hline \multirow{6}{*}{$\begin{array}{l}\text { Zhang et al } \\
(2016)^{57}\end{array}$} & $\mathrm{AHI}$ & 1389 & $0 / 3 / 2$ & 0.41 (0.21 to 0.61$), p<0.001^{*}$ & 5 \\
\hline & Desat time & 1414 & $0 / 4 / 2$ & $0.32(0.12$ to 0.51$), p<0.01^{*}$ & \\
\hline & ESS & 1383 & $0 / 3 / 2$ & 2.12 (0.89 to 3.35$), p<0.001^{*}$ & \\
\hline & $\mathrm{RDI}$ & 204 & $0 / 3 / 0$ & $-2.17(-11.80$ to 7.46$), p=0.66^{*}$ & \\
\hline & Sleeping efficiency & 444 & $0 / 3 / 0$ & $-1.60(-5.57$ to 2.37$), p=0.43^{*}$ & \\
\hline & $\begin{array}{l}\text { Time of sleep with } \\
\text { oxygen desaturation } \\
\text { under } 90 \%\end{array}$ & 1416 & $0 / 4 / 2$ & 0.32 (0.12 to 0.51$), p=0.001$ & \\
\hline
\end{tabular}

\section{*SMD.}

AHI, Apnoea-Hypopnoea Index; AMSTAR, Assessment of Multiple Systematic Reviews; CCs/COs/CSs, case-control/cohort/ cross-sectional studies; C-IMT, carotid intima-media thickness; DBP, diastolic blood pressure; ESS, Epworth Sleepiness Scale; HDL-C, high-density lipoprotein cholesterol; LDL-C, low-density lipoprotein cholesterol; MMSE, Mini Mental State Examination; OH, overt hypothyroidism; RDI, Respiratory Disturbance Index; SBP, systolic blood pressure; SCH, subclinical hypothyroidism; SMD, standardised mean difference; TC, total cholesterol; TG, total triglyceride; WMD, weighted mean difference; ES, Expected Shortfall

The conclusions of the included articles were summarised, and the number of randomised controlled trials/CC/CO/CS studies and patients included in each MA and the average AMSTAR score were analysed.

For the association between $\mathrm{OH}$ and other diseases, one $\mathrm{MA}^{39}$ has confirmed that breast cancer was significantly associated with $\mathrm{OH}$. This MA included one, two and three CC, CO and CS studies, respectively. The AMSTAR score was moderate. However, another $\mathrm{MA}^{65}$ has shown that $\mathrm{OH}$ was not considered a risk factor of breast cancer, and such study included 24571 participants and 12 CC study. Moreover, its AMSTAR score was high. Thus, the credibility of the conclusion is relatively high. One article ${ }^{43}$ has included $10 \mathrm{CO}$ studies and shown that $\mathrm{OH}$ was significantly associated with increased cardiac death, hospitalisation and all-cause mortality in patients with HF. The large sample size and high AMSTAR score increased its credibility. Based on the effect of $\mathrm{OH}$ on gestational diabetes, one $\mathrm{MA}^{37}$ has included 225427 patients in three
$\mathrm{CO}$ studies and shown that $\mathrm{OH}$ was a risk factor of gestational diabetes. The AMSTAR score was moderate.

Six MAs ${ }^{40} 4148647174$ have shown that pregnant women with $\mathrm{OH}$ were at high risk for preterm birth. The average number of patients was more than one million, and the average AMSTAR score was 8.8 (range: 8-10). By contrast, one $\mathrm{MA}^{40}$ has confirmed that maternal $\mathrm{OH}$ might be associated with high and low birth weight and it might reduce the risk of large for gestational age. The AMSTAR score of this article was 8 . These data can provide greater power regarding the credibility of the conclusion.

Additionally, $\mathrm{OH}$ was significantly associated with stroke, ${ }^{32}$ left ventricular diastolic function, ${ }^{33}$ carpal tunnel syndrome, ${ }^{49}$ obstructive sleep apnea ${ }^{57}$ and plasma homocysteine $;{ }^{58}$ the AMSTAR scores of MAs were from moderate to high quality. More high-quality evidence is needed to support these results.

For the association between SCH and other diseases, four MAs ${ }^{36596675}$ reported that SCH was associated with 
a significant increase in carotid intima-media thickness. These MAs have an average of 2420 patients, and an average AMSTAR score of 8.75. Larger study containing more patients will make the result more credible. All three MAs ${ }^{3052} 54$ have shown that the lack of association between SCH and fractures. A large number of patients and a high AMSTAR score increased the credibility of the conclusion. In addition, one $\mathrm{MA}^{60}$ has confirmed that $\mathrm{SCH}$ was associated with increased risk for fractures; therefore, more high-quality evidence is needed.

Two ${ }^{36} 42$ high-quality MAs have shown that serum total cholesterol, low-density lipoprotein cholesterol and triglyceride levels were significantly higher in patients with SCH than those with euthyroidism. However, no significant difference was observed in serum high-density lipoprotein cholesterol levels. SCH was associated with a significant decrease in fasting plasma glucose levels but not significantly associated with Body Mass Index. ${ }^{36}$ The AMSTAR score of this article was high. However, a small sample size decreased its credibility.

The included MAs had different conclusions regarding the role of $\mathrm{SCH}$ in blood pressure. One $\mathrm{MA}^{31}$ has shown that $\mathrm{SCH}$ was associated with a significant increase in diastolic blood pressure. However, the other two ${ }^{36} 56$ had a different conclusion. The former included 6 CS studies with 17323 patients, and the two other MAs had an average of 1.7 CC studies, $1.7 \mathrm{CO}$ studies and $5 \mathrm{CS}$ studies with an average of 25810 patients, and the average AMSTAR score for both MAs was 8.0. All three MAs have shown that $\mathrm{SCH}$ was associated with an increased systolic blood pressure.

Six MAs ${ }^{28} 4450637077$ have assessed the effects of SCH on CHD and cardiovascular mortality. Among these, three ${ }^{284477}$ have evaluated the association between SCH and CHD and confirmed that SCH was not significantly associated with an increased risk for CHD, whereas the other two studies ${ }^{5063}$ had a conflicting result. Two ${ }^{5070}$ MAs have shown that $\mathrm{SCH}$ was associated with an increased cardiovascular mortality rate from cardiovascular disease, and another two ${ }^{28} 44$ have revealed that SCH was not significantly associated with an increased mortality rate from cardiovascular disease. In addition, three studies ${ }^{28450}$ have concluded that SCH is not significantly associated with an increased risk for all-cause mortality. All the studies had moderate AMSTAR scores. Thus, the association between them should be further validated.

Two MAs ${ }^{34}$ have confirmed that SCH was not associated with MetS, and the AMSTAR scores were high. Three $\mathrm{MAs}^{29} 4547$ have investigated the effect of SCH on cognitive function and shown that SCH was not significantly associated with cognitive impairment. A large number of studies and patients and a high AMSTAR score increased the credibility of this conclusion. In addition, two $\mathrm{MAs}^{38}{ }^{53}$ have reported that $\mathrm{SCH}$ significantly increased the risk of complications from diabetes.

One $\mathrm{MA}^{48}$ has shown that maternal SCH is not significantly related with the occurrence of preterm birth, whereas the other four ${ }^{4164} 7174$ with more patients had a conflicting result, which showed that $\mathrm{SCH}$ increased the risk of preterm birth. Two MAs ${ }^{5164}$ have shown that maternal SCH is significantly associated with the risk for intrauterine growth restriction, and these MAs had a moderate AMSTAR score. Three MAs ${ }^{3564} 76$ have shown that maternal SCH also had a significant adverse effect on the intelligence of an offspring. However, the sample size of these MAs was small.

Two MAs ${ }^{68}{ }^{69}$ have indicated that individuals with $\mathrm{OH}$ have an increased risk of developing glaucoma. These MAs included 9 CC studies, 4 CO studies and 11 CC studies, and had an average AMSTAR score of 9. One MA ${ }^{72}$ has shown no significant association between non-alcoholic fatty liver disease as well as SCH and OH. However, another study ${ }^{73}$ has revealed that both individuals with $\mathrm{SCH}$ and $\mathrm{OH}$ are at higher risk for non-alcoholic fatty liver disease than those with euthyroid; therefore, more high-quality evidence is required.

In summary, when evaluating the association between hypothyroidism and other diseases, the hypothyroidism activity index, follow-up duration, baseline demographic data and clinical characteristics should also be considered in evaluating the role of hypothyroidism in other diseases.

\section{CONCLUSIONS}

The methodological quality of the included MAs on the association between hypothyroidism and other diseases was moderate to high. MAs with high qualities confirmed that hypothyroidism was significantly associated with cardiovascular diseases, MetS, preterm birth and neonatal outcomes. Consideration of scientific quality when formulating conclusions should be made explicit and more attention should be paid to improving the methodological quality of MAs, increasing their applicability for clinical decision-making.

\section{Strengths and limitations}

To the best of our knowledge, this study first assessed the methodological quality of MAs on the association between hypothyroidism and other diseases. The included MAs were randomly selected without restriction and followed rigorous inclusion and exclusion criteria. Our study has several limitations. First, the AMSTAR appraisal process was difficult to implement when the reporting quality was poor. This could be attributed to space restrictions in some journals. Second, we tried our best to make a conversion between OR and RR by extracting raw data from MAs, but some data were not obtained.

Contributors LT, QG and CG conceived and designed the study. FS and YQ performed the experiments. FS wrote the paper. LT and CG reviewed and edited the manuscript. All authors read and approved the manuscript.

Funding This research received the grant from National Natural Science Foundation of China and Province Natural Science Foundation of Gansu (grant nos and 17JR5RA041).

Competing interests None declared.

Patient consent for publication Obtained. 
Provenance and peer review Not commissioned; externally peer reviewed.

Data sharing statement No additional data are available.

Open access This is an open access article distributed in accordance with the Creative Commons Attribution Non Commercial (CC BY-NC 4.0) license, which permits others to distribute, remix, adapt, build upon this work non-commercially, and license their derivative works on different terms, provided the original work is properly cited, appropriate credit is given, any changes made indicated, and the use is non-commercial. See: http://creativecommons.org/licenses/by-nc/4.0/.

\section{REFERENCES}

1. Vanderpump MP, Tunbridge WM. Epidemiology and prevention of clinical and subclinical hypothyroidism. Thyroid 2002;12:839-47.

2. Hollowell JG, Staehling NW, Flanders WD, et al. Serum TSH, T(4), and thyroid antibodies in the United States population (1988 to 1994): National Health and Nutrition Examination Survey (NHANES III). J Clin Endocrinol Metab 2002;87:489-99.

3. Marwaha RK, Tandon N, Ganie MA, et al. Status of thyroid function in Indian adults: two decades after universal salt iodization. J Assoc Physicians India 2012;60:32-6.

4. Biondi B, Bartalena L, Chiovato L, et al. Recommendations for treatment of hypothyroidism with levothyroxine and levotriiodothyronine: a 2016 position statement of the Italian Society of Endocrinology and the Italian Thyroid Association. J Endocrinol Invest 2016;39:1465-74.

5. Sun X, Sun Y, Li WC, et al. Association of thyroid-stimulating hormone and cardiovascular risk factors. Intern Med 2015;54:2537-44.

6. Nanchen D, Gussekloo J, Westendorp RG, et al. Subclinical thyroid dysfunction and the risk of heart failure in older persons at high cardiovascular risk. J Clin Endocrinol Metab 2012;97:852-61.

7. Asvold BO, Bjøro T, Nilsen TI, et al. Thyrotropin levels and risk of fatal coronary heart disease: the HUNT study. Arch Intern Med 2008;168:855-60.

8. Canpolat AG, Kav T, Sivri B, et al. Effects of L-thyroxine on gastric motility and ghrelin in subclinical hypothyroidism: a prospective study. J Clin Endocrinol Metab 2013;98:E1775-E1779.

9. Resta F, Triggiani V, Barile G, et al. Subclinical hypothyroidism and cognitive dysfunction in the elderly. Endocr Metab Immune Disord Drug Targets 2012;12:260-7.

10. Formiga F, Ferrer A, Padros G, et al. Thyroid status and functional and cognitive status at baseline and survival after 3 years of followup: the OCTABAIX study. Eur J Endocrinol 2014;170:69-75.

11. Waring AC, Rodondi N, Harrison S, et al. Thyroid function and prevalent and incident metabolic syndrome in older adults: the Health, Ageing and Body Composition Study. Clin Endocrinol 2012;76:911-8.

12. Wang CY, Chang TC, Chen MF. Associations between subclinical thyroid disease and metabolic syndrome. Endocr J 2012;59:911-7.

13. Garin MC, Arnold AM, Lee JS, et al. Subclinical thyroid dysfunction and hip fracture and bone mineral density in older adults: the cardiovascular health study. J Clin Endocrinol Metab 2014;99:2657-64.

14. Flynn RW, Bonellie SR, Jung RT, et al. Serum thyroid-stimulating hormone concentration and morbidity from cardiovascular disease and fractures in patients on long-term thyroxine therapy. J Clin Endocrinol Metab 2010;95:186-93.

15. Nordmann AJ, Kasenda B, Briel M. Meta-analyses: what they can and cannot do. Swiss Med Wkly 2012;142:w13518.

16. Dong J, Teng G, Wei T, et al. Methodological quality assessment of meta-analyses and systematic reviews of probiotics in inflammatory bowel disease and pouchitis. PLoS One 2016;11:e0168785.

17. Clarke S, Wilson ML, Terhaar M. Using dashboard technology and clinical decision support systems to improve heart team efficiency and accuracy: review of the literature. Stud Health Technol Inform 2016;225:364-6.

18. Pieper D, Mathes T, Eikermann M. Can AMSTAR also be applied to systematic reviews of non-randomized studies? BMC Res Notes 2014;7:609.

19. Gagnier JJ, Kellam PJ. Reporting and methodological quality of systematic reviews in the orthopaedic literature. J Bone Joint Surg Am 2013;95:e77-7.

20. Remschmidt C, Wichmann O, Harder T. Methodological quality of systematic reviews on influenza vaccination. Vaccine 2014;32:1678-84.

21. Tian J, Zhang J, Ge L, et al. The methodological and reporting quality of systematic reviews from China and the USA are similar. J Clin Epidemiol 2017;85:50-8.
22. Shea BJ, Grimshaw JM, Wells GA, et al. Development of AMSTAR: a measurement tool to assess the methodological quality of systematic reviews. BMC Med Res Methodol 2007;7:10.

23. Landis JR, Koch GG. The measurement of observer agreement for categorical data. Biometrics 1977;33:159-74.

24. Cai YF, Shi JP. [Meta analysis on the relationship between subclinical hypothyroidism and the levels of systolic blood pressure]. Zhonghua Liu Xing Bing Xue Za Zhi 2011;32:55-9.

25. Chen $X$, Zhang N, Zhang WL, et al. [Meta-analysis on the association between subclinical hypothyroidism and the left ventricular functions under Doppler echocardiography]. Zhonghua Liu Xing Bing Xue Za Zhi 2011;32:1269-74.

26. Rodondi N, Aujesky D, Vittinghoff E, et al. Subclinical hypothyroidism and the risk of coronary heart disease: a systematic review and meta-analysis. Journal Of General Internal Medicine 2005;20:89.

27. Rodondi N, Aujesky D, Vittinghoff E, et al. Subclinical hypothyroidism and the risk of coronary heart disease: a meta-analysis. Am J Med 2006;119:541-51.

28. Rodondi N, den Elzen WP, Bauer DC, et al. Subclinical hypothyroidism and the risk of coronary heart disease and mortality. JAMA 2010;304:1365-74.

29. Akintola AA, Jansen SW, van Bodegom D, et al. Subclinical hypothyroidism and cognitive function in people over 60 years: a systematic review and meta-analysis. Front Aging Neurosci 2015;7:150.

30. Blum MR, Bauer DC, Collet TH, et al. Subclinical thyroid dysfunction and fracture risk: a meta-analysis. JAMA 2015;313:2055-65.

31. Cai Y, Ren Y, Shi J. Blood pressure levels in patients with subclinical thyroid dysfunction: a meta-analysis of cross-sectional data. Hypertens Res 2011;34:1098-105.

32. Chaker L, Baumgartner C, Ikram MA, et al. Subclinical thyroid dysfunction and the risk of stroke: a systematic review and metaanalysis. Eur J Epidemiol 2014;29:791-800.

33. Chen X, Zhang N, Cai Y, et al. Evaluation of left ventricular diastolic function using tissue Doppler echocardiography and conventional doppler echocardiography in patients with subclinical hypothyroidism aged <60 years: a meta-analysis. J Cardiol 2013;61:8-15.

34. Eftekharzadeh A, Khamseh ME, Farshchi A, et al. The association between subclinical hypothyroidism and metabolic syndrome as defined by the ATP III Criteria. Metab Syndr Relat Disord 2016;14:137-44.

35. Fan $\mathrm{X}, \mathrm{Wu} \mathrm{L}$. The impact of thyroid abnormalities during pregnancy on subsequent neuropsychological development of the offspring: a meta-analysis. J Matern Fetal Neonatal Med 2016;29:3971-6.

36. Gao N, Zhang W, Zhang YZ, et al. Carotid intima-media thickness in patients with subclinical hypothyroidism: a meta-analysis. Atherosclerosis 2013;227:18-25.

37. Gong LL, Liu H, Liu LH. Relationship between hypothyroidism and the incidence of gestational diabetes: a meta-analysis. Taiwan J Obstet Gynecol 2016;55:171-5.

38. Han C, He X, Xia X, et al. Subclinical hypothyroidism and type 2 diabetes: a systematic review and meta-analysis. PLoS One 2015;10:e0135233

39. Hardefeldt PJ, Eslick GD, Edirimanne S. Benign thyroid disease is associated with breast cancer: a meta-analysis. Breast Cancer Res Treat 2012;133:1169-77.

40. Hou J, Yu P, Zhu H. The impact of maternal hypothyroidism during pregnancy on neonatal outcomes_A systematic review and metaanalysis (Gynecological Endocrinology (2015)). Endocrinology 2016.

41. Li M, Wang SW, Wu FL, et al. Ethnic differences in preterm birth risks for pregnant women with thyroid dysfunction or autoimmunity: a meta-analysis. Biomed Environ Sci 2016;29:724-33.

42. Liu XL, He S, Zhang SF, et al. Alteration of lipid profile in subclinical hypothyroidism: a meta-analysis. Med Sci Monit 2014;20:1432-41.

43. Ning N, Gao D, Triggiani V, et al. Prognostic role of hypothyroidism in heart failure: a meta-analysis. Medicine 2015;94:e1159.

44. Ochs N, Auer R, Bauer DC, et al. Meta-analysis: subclinical thyroid dysfunction and the risk for coronary heart disease and mortality. Ann Intern Med 2008;148:832-45.

45. Pasqualetti G, Pagano G, Rengo G, et al. Subclinical hypothyroidism and cognitive impairment: systematic review and meta-analysis. $J$ Clin Endocrinol Metab 2015;100:4240-8.

46. Pergialiotis V, Konstantopoulos P, Prodromidou A, et al. Management of endocrine disease: the impact of subclinical hypothyroidism on anthropometric characteristics, lipid, glucose and hormonal profile of PCOS patients: a systematic review and meta-analysis. Eur J Endocrinol 2017;176:R159-R166.

47. Rieben C, Segna D, da Costa BR, et al. Subclinical thyroid dysfunction and the risk of cognitive decline: a meta-analysis of prospective cohort studies. J Clin Endocrinol Metab 2016;101:4945-54. 
48. Sheehan PM, Nankervis A, Araujo Júnior E, et al. Maternal thyroid disease and preterm birth: systematic review and meta-analysis. $J$ Clin Endocrinol Metab 2015;100:4325-31.

49. Shiri R. Hypothyroidism and carpal tunnel syndrome: a metaanalysis. Muscle Nerve 2014;50:879-83.

50. Singh S, Duggal J, Molnar J, et al. Impact of subclinical thyroid disorders on coronary heart disease, cardiovascular and all-cause mortality: a meta-analysis. Int J Cardiol 2008;125:41-8.

51. Tong Z, Xiaowen Z, Baomin C, et al. The effect of subclinical maternal thyroid dysfunction and autoimmunity on intrauterine growth restriction: a systematic review and meta-analysis. Medicine 2016;95:e3677.

52. Wirth CD, Blum MR, da Costa BR, et al. Subclinical thyroid dysfunction and the risk for fractures: a systematic review and metaanalysis. Ann Intern Med 2014;161:189-99.

53. Wu J, Yue S, Geng J, et al. Relationship between diabetic retinopathy and subclinical hypothyroidism: a meta-analysis. Sci Rep 2015;5:12212.

54. Yan Z, Huang $\mathrm{H}$, Li J, et al. Relationship between subclinical thyroid dysfunction and the risk of fracture: a meta-analysis of prospective cohort studies. Osteoporos Int 2016;27:115-25.

55. Yang L, Lv X, Yue F, et al. Subclinical hypothyroidism and the risk of metabolic syndrome: a meta-analysis of observational studies. Endocr Res 2016;41:158-65.

56. Ye $\mathrm{Y}, \mathrm{Xie} \mathrm{H}$, Zeng $\mathrm{Y}$, et al. Association between subclinical hypothyroidism and blood pressure--a meta-analysis of observational studies. Endocr Pract 2014;20:150-8.

57. Zhang M, Zhang W, Tan J, et al. Role of hypothyroidism in obstructive sleep apnea: a meta-analysis. Curr Med Res Opin 2016;32:1059-64.

58. Zhou Y, Chen Y, Cao X, et al. Association between plasma homocysteine status and hypothyroidism: a meta-analysis. Int J Clin Exp Med 2014;7:4544-53.

59. Yao K, Zhao T, Zeng L, et al. Non-invasive markers of cardiovascular risk in patients with subclinical hypothyroidism: A systematic review and meta-analysis of 27 case control studies. Sci Rep 2018;8:4579.

60. Yang $R$, Yao L, Fang Y, et al. The relationship between subclinical thyroid dysfunction and the risk of fracture or low bone mineral density: a systematic review and meta-analysis of cohort studies. $J$ Bone Miner Metab 2018;36:209-20.

61. Thompson W, Russell G, Baragwanath G, et al. Maternal thyroid hormone insufficiency during pregnancy and risk of neurodevelopmental disorders in offspring: a systematic review and meta-analysis. Clin Endocrinol 2018;88:575-84.

62. Zhou JB, Li HB, Zhu XR, et al. Subclinical hypothyroidism and the risk of chronic kidney disease in T2D subjects: A case-control and dose-response analysis. Medicine 2017;96:e6519.

63. Sun J, Yao L, Fang Y, et al. Relationship between subclinical thyroid dysfunction and the risk of cardiovascular outcomes: a systematic review and meta-analysis of prospective cohort studies. Int $J$ Endocrinol 2017;2017:8130796:1-15.

64. Liu $\mathrm{Y}$, Chen $\mathrm{H}$, Jing $\mathrm{C}$, et al. The association between maternal subclinical hypothyroidism and growth, development, and childhood intelligence: a meta-analysis. J Clin Res Pediatr Endocrinol 2018;10:153-61.
65. Fang Y, Yao L, Sun J, et al. Does thyroid dysfunction increase the risk of breast cancer? A systematic review and meta-analysis. J Endocrinol Invest 2017;40:1035-47.

66. Aziz M, Kandimalla Y, Machavarapu A, et al. Effect of thyroxin treatment on carotid intima-media thickness (CIMT) reduction in patients with subclinical hypothyroidism (SCH): a meta-analysis of clinical trials. J Atheroscler Thromb 2017;24:643-59.

67. Zhang $\mathrm{Y}$, Wang $\mathrm{H}$, Pan $\mathrm{X}$, et al. Patients with subclinical hypothyroidism before 20 weeks of pregnancy have a higher risk of miscarriage: A systematic review and meta-analysis. PLoS One 2017;12:e0175708

68. Wang S, Liu Y, Zheng G. Hypothyroidism as a risk factor for open angle glaucoma: a systematic review and meta-analysis. PLoS One 2017;12:e0186634

69. Thvilum M, Brandt F, Brix TH, et al. The interrelation between hypothyroidism and glaucoma: a critical review and meta-analyses. Acta Ophthalmol 2017;95:759-67.

70. Ning Y, Cheng YJ, Liu LJ, et al. What is the association of hypothyroidism with risks of cardiovascular events and mortality? A meta-analysis of 55 cohort studies involving 1,898,314 participants. BMC Med 2017;15:21.

71. Parizad Nasirkandy M, Badfar G, Shohani M, et al. The relation of maternal hypothyroidism and hypothyroxinemia during pregnancy on preterm birth: An updated systematic review and meta-analysis. Int $J$ Reprod Biomed 2017;15:543-52.

72. Jaruvongvanich V, Sanguankeo A, Upala S. Nonalcoholic fatty liver disease is not associated with thyroid hormone levels and hypothyroidism: a systematic review and meta-analysis. Eur Thyroid J 2017;6:208-15

73. He W, An X, Li L, et al. Relationship between hypothyroidism and non-alcoholic fatty liver disease: a systematic review and metaanalysis. Front Endocrinol 2017;8:335.

74. Wang S, Li M, Chu D, et al. [Clinical or subclinical hypothyroidism and thyroid autoantibody before 20 weeks pregnancy and risk of preterm birth: a systematic review]. Zhonghua Fu Chan Ke Za Zhi 2014;49:816-22.

75. Wang HL, Zhang N, Zhang WL, et al. Associations between subclinical hypothyroidism and carotid intima media thickness: a meta analysis. Chinese General Practice 2013;16:479-82.

76. XY X, Xie M, Li Z, et al. A meta-analysis about the impact on the mental development of the offspring by pregnant women with subclinical hypothyroidism. J Clin Intern Med 2014;31:46-8.

77. Zhang N, Zhang WL, Shi JP. A meta-analysis on relationship between subclinical hypothyroidism and coronary heart disease. Chinese General Practice 2011;14:125-9.

78. Zhou JB, Zhu XR, Zhao YY, et al. Relationship between chronic kidney disease and subclinical hypothyroidism in T2DM subjects: a case-control and dose-response analysis. J ClinPathol Res 2016;36:1096-102.

79. X J, X G, Z L, et al. Relationship between the subclinical thyroid dysfunction and the risk for fracture: A meta analysis.

80. Collaboration TC. Cochrane handbook for systematic reviews of interventions. $2011 \mathrm{http}: / /$ handbook-5-1.cochrane.org/.

81. Egger M, Davey Smith G, Schneider M, et al. Bias in meta-analysis detected by a simple, graphical test. BMJ 1997;315:629-34. 